\title{
Originals
}

\section{Relation of Kidney Size to Kidney Function in Early Insulin-Dependent Diabetes}

\author{
J. García Puig, F. Mateos Antón, C. Grande, L. F. Pallardo, F. Arnalich, A. Gil, J. J. Vázquez \\ and A. Montero García \\ Department of Internal Medicine and Clinical Biopathology, La Paz Hospital, Autonomous University, Madrid, Spain
}

\begin{abstract}
Summary. Renal function and renal size have been studied in ten early insulin-dependent diabetic patients and in ten matched control subjects. Glomerular filtration rate, renal plasma flow and radiological kidney size were determined in each subject. Glomerular filtration rate and renal plasma flow were increased in diabetics (mean \pm SD: $169.6 \pm 16.1$ and $690.1 \pm 52.6 \mathrm{ml} / \mathrm{min} / 1.73 \mathrm{~m}^{2}$, respectively) compared with controls $(120.6 \pm 9.7$ and $605.9 \pm 67.2 \mathrm{ml} /$ $\min / 1.73 \mathrm{~m}^{2} ; p<0.001$ and $\left.p<0.01\right)$. Calculated kidney weight corrected to $1.73 \mathrm{~m}^{2}$ of body surface area was elevated in diabetics $(385.2 \pm 29.0 \mathrm{~g})$ with respect to controls $(277.5 \pm 17.5 \mathrm{~g} ; p<0.001)$. No significant differences were found between diabetics and control subjects when glomerular filtration rate was expressed per gram calculated kidney weight, while renal plasma flow was significantly lower in diabetics than control subjects when so expressed $(p<0.01)$. A positive correlation was found between glomerular filtration rate, renal plasma flow and kidney size in both controls and diabetics $(p<0.01$ in all cases). These findings support the conclusion that in the early state of diabetes glomerular hyperfunction is related to enlargement of the kidneys and augmented renal plasma flow.
\end{abstract}

Key words: Insulin-dependent diabetes, kidney size, glomerular filtration rate, renal plasma flow, renal function

Kidney function is often abnormal in diabetics. In early insulin-dependent diabetes, the glomerular filtration rate (GRF) is usually elevated [1-6]. Glomerular permeability and urinary albumin excretion are typically normal in short-term diabetes with- out proteinuria [5], suggesting that abnormal filter properties are not the mechanism behind the high filtration rate. Renal plasma flow (RPF) is also elevated in these patients, so increased capillary pressure may be responsible for the elevation in GFR. Alternatively, the increment in GFR may be due to increased kidney size [6]. The present study was carried out to determine whether the levels of GFR and RPF in early insulin-dependent diabetes are related to kidney size.

\section{Subjects and Methods}

\section{Patients and Control Groups}

Five males and five females with insulin-dependent diabetes mellitus were studied. Their ages ranged from 11 to 24 years (average 18 years), and they had had the disease for 1-4 years. Healthy volunteers served as controls and were chosen to correspond with diabetics in sex, age and body surface area (maximum difference $0.05 \mathrm{~m}^{2}$ ). Their individual weights had not changed significantly since diagnosis and were near their ideal weights according to Life Insurance Tables (Table 1). All diabetics were treated with isophane insulin (NPH) in two daily doses (morning and evening) during the previous 6 months. Periodically, fasting serum glucose and glycosuria were determined and insulin dose readjusted in order to achieve reasonable glycaemic control. Patients and controls were receiving no medication, except for insulin, during the 6 months before study; they all took their normal diets during this period and all volunteered to participate after the details of the study were fully explained.

\section{Procedures}

Subjects were tested in the early morning after an overnight fast, and the patients' usual insulin was withheld after the clearance test. On the previous day, patients received their normal doses of insulin; blood glucose was determined every $2 \mathrm{~h}$ during a $24-\mathrm{h}$ urine collection period and every $\mathbf{3 0} \mathrm{min}$ during the renal function test.

GFR was determined by means of creatinine clearance. Clearance of sodium aminohippurate (Merck Sharp \& Dohme) using a 
Table 1. Clinical data of insulin-dependent diabetics and control subjects

\begin{tabular}{|c|c|c|c|c|c|c|c|c|c|c|}
\hline $\begin{array}{l}\text { Case } \\
\text { no. }\end{array}$ & Sex & $\begin{array}{l}\text { Age } \\
\text { (years) }\end{array}$ & $\begin{array}{l}\text { Duration } \\
\text { of diabetes } \\
\text { (years) }\end{array}$ & $\begin{array}{l}\% \text { Ideal } \\
\text { body } \\
\text { weight }^{\mathrm{a}}\end{array}$ & $\begin{array}{l}\text { Usual dose } \\
\text { of insulin } \\
\text { isophane } \\
\text { (units) }\end{array}$ & $\begin{array}{l}\text { Evening } \\
\text { dose of insu- } \\
\text { lin }^{c} \text { isophane } \\
\text { (units) }\end{array}$ & $\begin{array}{l}\text { Range of } \\
\text { blood } \\
\text { glucose } \\
(\mathrm{mmol} / \mathrm{l})\end{array}$ & $\begin{array}{l}\text { Range of } \\
\text { glycosuria }^{b} \\
(\mathrm{mmol} / \text { day) }\end{array}$ & $\begin{array}{l}\text { Basal blood } \\
\text { glucose } \\
(\mathrm{mmol} / \mathrm{l})\end{array}$ & $\begin{array}{l}\text { Urine } \\
\text { glucose }^{\mathrm{c}} \\
\text { (mmol/day) }^{\text {(mmol }}\end{array}$ \\
\hline \multicolumn{11}{|c|}{ Diabetic subjects } \\
\hline 1 & $F$ & 23 & 3 & +10.2 & $18-18$ & 18 & $5.4-10.1$ & $0.3-1.1$ & 7.1 & 98 \\
\hline 2 & $\mathrm{M}$ & 11 & 2 & -4.3 & $20-18$ & 18 & $4.2-10.2$ & $0.7-2.2$ & 9.4 & 161 \\
\hline 3 & $\mathrm{~F}$ & 28 & 4 & +13.6 & $34-28$ & 24 & $3.3-9.7$ & $0.2-1.3$ & 5.8 & 127 \\
\hline 4 & $\mathrm{~F}$ & 12 & 3 & -0.3 & $13-13$ & 10 & $4.7-9.2$ & $0.4-1.2$ & 6.7 & 108 \\
\hline 5 & $\mathbf{M}$ & 9 & 1 & -6.7 & $22-19$ & 15 & $5.6-10.8$ & $0.6-2.1$ & 9.1 & 154 \\
\hline 6 & $\mathrm{~F}$ & 15 & 4 & +18.9 & $36-36$ & 36 & $3.7-13.3$ & $0.8-1.6$ & 8.6 & 104 \\
\hline 7 & M & 15 & 3 & +11.1 & $27-25$ & 23 & $4.1-9.0$ & $0.3-2.1$ & 7.9 & 137 \\
\hline 8 & $\mathbf{F}$ & 23 & 3 & +1.6 & $20-20$ & 17 & $4.5-6.7$ & $0.2-1.0$ & 4.8 & 84 \\
\hline 9 & $\mathbf{M}$ & 24 & 3 & +7.5 & $23-25$ & 25 & $3.2-8.2$ & $0.5-0.9$ & 4.2 & 75 \\
\hline 10 & $\mathbf{M}$ & 19 & 1 & -4.6 & $18-12$ & 11 & $4.6-8.8$ & $0.4-0.2$ & 5.1 & 44 \\
\hline Mean & & 18.1 & 2.3 & +4.7 & $23.1-20.3$ & 19.7 & $4.3-9.6$ & $0.4-1.4$ & 6.9 & 109 \\
\hline SD & & 6.1 & 1.1 & 8.8 & $7.3-5.6$ & 7.7 & $0.8-1.8$ & $0.2-0.5$ & 1.9 & 36 \\
\hline \multicolumn{11}{|c|}{ Control subjects } \\
\hline 1 & $\mathrm{~F}$ & 23 & & +8.7 & & & & & 4.7 & \\
\hline 2 & $\mathbf{M}$ & 11 & & +2.4 & & & & & 5.3 & \\
\hline 3 & $\mathrm{~F}$ & 28 & & +6.5 & & & & & 4.1 & \\
\hline 4 & $\mathbf{F}$ & 12 & & -4.3 & & & & & 3.7 & \\
\hline 5 & $\mathbf{M}$ & 9 & & -9.6 & & & & & 3.9 & \\
\hline 6 & $\mathbf{F}$ & 15 & & +12.4 & & & & & 5.4 & \\
\hline 7 & M & 15 & & +16.7 & & & & & 3.8 & \\
\hline 8 & $\mathrm{~F}$ & 23 & & +7.4 & & & & & 4.6 & \\
\hline 9 & M & 24 & & -0.4 & & & & & 4.0 & \\
\hline 10 & $\mathbf{M}$ & 19 & & -5.9 & & & & & 3.4 & \\
\hline \multicolumn{2}{|c|}{ Mean } & 18.1 & & +3.4 & & & & & 4.4 & \\
\hline \multicolumn{2}{|l|}{ SD } & 6.1 & & 8.4 & & & & & 0.6 & \\
\hline \multicolumn{2}{|l|}{$p$} & NS & & NS & & & & & $<0.01$ & \\
\hline
\end{tabular}

a Metropolitan Life Insurance Co. Statistical Bulletin, November-December 1959

b During the previous 6 months (insulin doses refer to maximum morning and evening doses)

c The day before kidney function test

constant infusion technique, was used for estimating RPF [4], and performed simultaneously with determinations of GFR. All clearance values were corrected to $1.73 \mathrm{~m}^{2}$ body surface area. Kidney size was estimated on the basis of an X-ray film. In those cases in which the renal silhouettes were not visualized an IV excretory urogram was obtained. Focus-film distance was $110 \mathrm{~cm}$. Kidney measurements were made by one of the authors (F. A.) who was ignorant of the renal function tests and of the subject's category (diabetic or control). Kidney length was measured as the maximum distance from pole to pole in $\mathrm{cm}$. Kidney width was the maximum distance from lateral kidney surface to the tangent line of the medial borders of the kidney in $\mathrm{cm}$. The kidney weight was calculated using Moell's linear equation [7] for the sum of both kidneys on a logarithmic scale: $y=1.206 x-0.180 ; x=\log$ of the total kidney area in $\mathrm{cm}^{2}$ and $\mathrm{y}=$ kidney weight in grams. The renal index was obtained from a formula proposed by Friedenberg et al. [8]. Renal index $=\frac{\text { length }(\mathrm{cm}) \times \text { width }(\mathrm{cm})}{\text { body surface }\left(\mathrm{cm}^{2}\right)}$.

\section{Analytical Methods}

Creatinine concentrations were determined by an enzymatic technique [9] and sodium aminohippurate concentrations were measured using the methods of Bratton and Marshall [10]. Blood and urine glucose were determined by an ortho-toluidine method.

\section{Statistical Analysis}

After verifying that samples conformed to a normal distribution (Kolmogorov-Smirnov test) and that there were no differences in variance (Fisher's F-test), the Student's $t$ test was applied with $p<0.05$ being considered statistically significant. Correlations were made according to Pearson's correlation coefficient.

\section{Results}

Data describing the clinical condition of the patients and control subjects are presented in Table 1. During the previous 6 months all diabetics had reasonable glycaemic control (fasting blood glucose $<11 \mathrm{mmol} / 1$ and glycosuria $<167 \mathrm{mmol} /$ day, determined twice monthly) which had been improved by the day before 


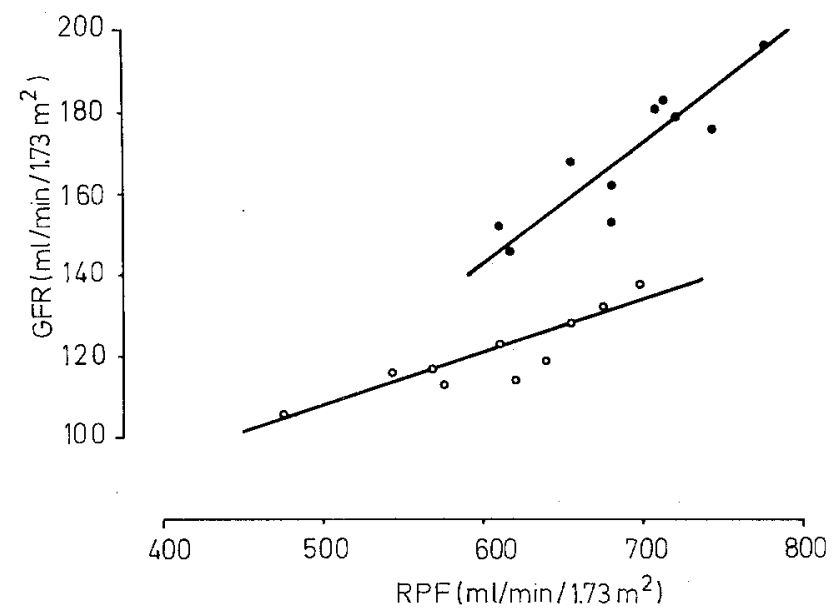

Fig. 1. Relation between glomerular filtration rate (GFR) and renal plasma flow (RPF) in diabetics $(y=0.27 x-18.71$; $r=0.89 ; p<0.01)$ and controls $(0)(y=0.13 x+43.19$; $r=0.89 ; p<0.01$ )

the study (basal blood glucose below $10 \mathrm{mmol} / \mathrm{l}$ and urine glucose $<139 \mathrm{mmol} /$ day).

Table 2 shows the GFR, RPF, and filtration fraction $(\mathrm{FF}=\mathrm{GFR} / \mathrm{RPF})$ data together with the radiological kidney measurements in diabetic and control subjects. The absolute levels of GFR, RPF and filtration fraction were significantly higher in diabetics than in control subjects. When expressed in terms of kidney weight, GFR was similar in diabetics and in control subjects while RPF was significantly lower in diabetics. Kidneys were larger in the diabetic than in the control group, as shown by the significantly greater surface areas and calculated weights. Right and left renal indices were also significantly greater in diabetics than in control subjects.

Figure 1 shows the relation between GFR and RPF in diabetics and control subjects. Similar correlation coefficients $(r=0.89 ; p<0.01)$ were obtained in both groups.

Figures 2 and 3 show the relation between calculated kidney weight and GFR and RPF respectively. Significant correlations were obtained between calculated kidney weight and GFR, and between calculated kidney weight and RPF, both in diabetics and controls.

No correlation could be found between either the degree or duration of diabetes and the changes in renal function or kidney size.

\section{Discussion}

Nephropathy is a serious complication of diabetes, and it is therefore of interest to clarify its pathogenesis and chronology. Usually, GFR is ele- 


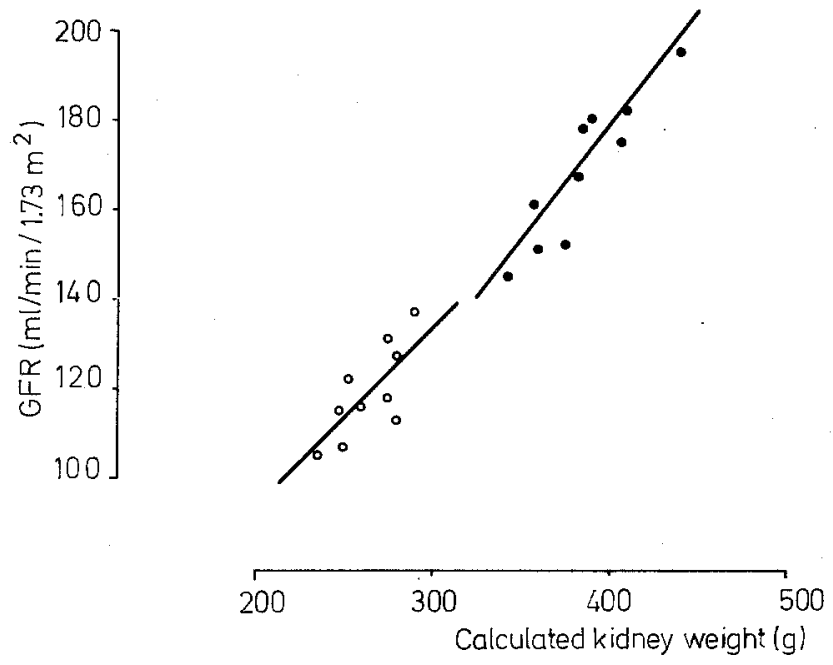

Fig. 2. Relation between glomerular filtration rate (GFR) and calculated kidney weight in diabetics $(\bullet)(y=0.51 x-24.9 ; r=$ $0.91 ; p<0.001)$ and controls $(0)(y=0.40 x+13.78 ; r=0.73$; $p<0.01)$. Kidney weight was calculated using Moëll's linear equation [7]

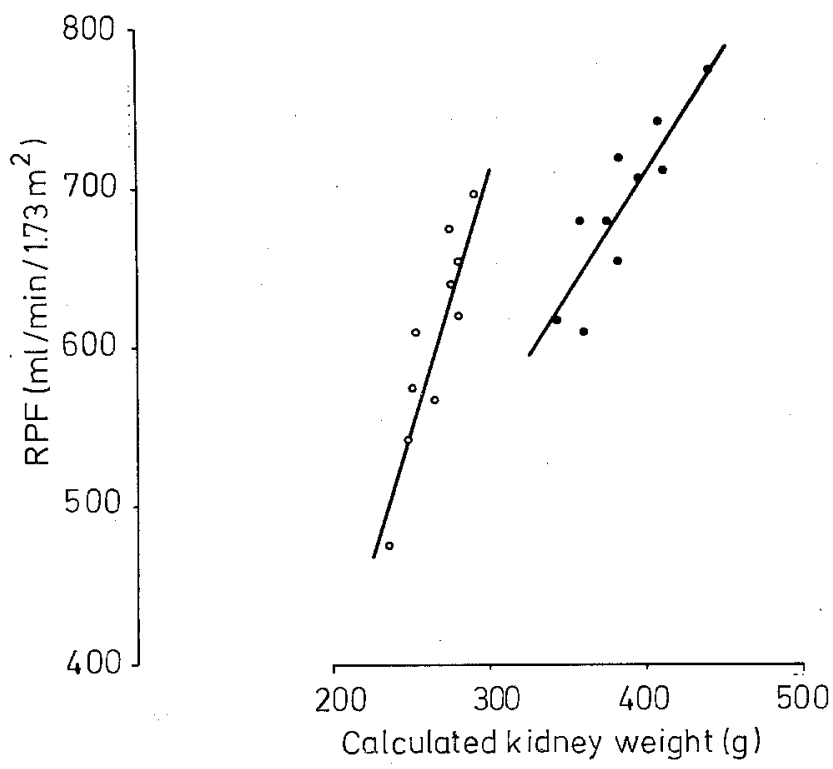

Fig. 3. Relation between renal plasma flow (RPF) and calculated kidney weight in diabetics $(\bullet)(y=1.59 x+74.67 ; r=0,88$; $p<0.001)$ and controls $(0)(y=3.43 x-304.57 ; r=0.91$; $p<0.001)$. Kidney weight was calculated using Moëll's linear equation [7]

vated in diabetics during the first few years of the disease. Recent studies suggest the elevation in GFR to be related either to changes in kidney size or to the metabolic disorders underlying diabetes [11]. The present investigations failed to show a positive correlation between the degree or duration of diabetes and changes in kidney function or renal size. In fact patients showed increased GFR and RPF in spite of maintenance of acceptable glycaemic control of their disease, and similar elevations in GFR and RPF were observed between short-term diabetics with different durations of their disease. However, Johansen and Hansen [12] linked renal hypertrophy and hyperfunction in early diabetes to growth hormone hypersecretion, which reaches its maximum values when the disease is uncontrolled. Moreover, Mogensen and Andersen [13] found that adequate insulin treatment reduced the elevated GFR and serum growth hormone concentrations in diabetics.

The present results show a clear relation between kidney size and glomerular hyperfunction in diabetics. Our findings agree fully with the correlations observed by Mogensen and Andersen [5] between calculated renal weight, GFR and RPF in diabetics. Differences in the absolute values for renal indices obtained in the two studies probably relate to the fact that these authors used only male subjects.

It is of interest to consider the mechanisms possibly responsible for the increase in GFR seen in early insulin-dependent diabetes. The determining factors of glomerular ultrafiltration are the hydrostatic and oncotic pressure gradients between plasma and Bowman's space, the ultrafiltration coefficient (basement membrane permeability multiplied by filtration surface) and RPF [14]. A definite study of the first two factors requires micropuncture techniques so that their role in alterations of renal function in human diabetics is unknown. The increase in GFR characteristic of early diabetes suggests that glomerular basement membrane permeability is modified, but this hypothesis has not been confirmed by studies of low molecular weight dextran clearances $[15,16]$. The fact that the kidneys are enlarged in diabetics points to an elevation in the ultrafiltration coefficient due to an increase in filtration surface. This notion is supported by the positive correlation between GFR and calculated kidney weight and by the fact that GFR expressed per gram kidney weight was similar in diabetics and control subjects. Furthermore, bidimensional studies verify an increase in filtration surface in human diabetes as well as in experimental streptozotocin induced diabetes [17-21].

Although an increase in filtration surface can account for a raised GFR, this factor alone cannot be held responsible for it in diabetics. The present study demonstrates that RPF is greater in diabetics of short duration than in control subjects but less than predicted for kidneys of the size seen in diabetics. The variation in RPF parallels the increment in GFR in diabetics, but their filtration fraction is larger and the ratio between RPF and calculated kidney weight is smaller than in control subjects. Taken together, 
these observations suggest that an elevation in filtration pressure might be the essential determining factor of the increased GFR seen in early insulin-dependent diabetes [16]. We conclude, therefore, that the glomerular hyperfunction characteristic of the initial stages of diabetes is probably caused by a combination of at least two factors: enhancement of filtration surface secondary to increased kidney size, which leads to a raised ultrafiltration coefficient, and an elevation of the RPF.

Acknowledgements. We gratefully acknowledge the valuable advice and helpful criticism of Dr. C. E. Mogensen. Professor J. Ortiz Vázquez kindly supervised the preparation of the manuscript.

\section{References}

1. Stalder G, Schmid R, Wolff MV (1960) Funktionelle mikroangiopathie der Nieren beim behandelten diabetes mellitus im Kindesalter. Dtsch Med Wochenschr 85: 346-350

2. Ditzel J, Junker K (1972) Abnormal filtration rate, renal plasma flow and renal protein excretion in recent and shortterm diabetes. $\mathrm{Br}$ Med J 2: 13-19

3. Mogensen CE (1973) Elevated glomerular filtration rate in insulin treated short-term diabetes: Non-dependence of the actual blood sugar level. Acta Med Scand 194: 559-561

4. Mogensen CE - (1971) Glomerular filtration rate and renal plasma flow in short-term and long-term juvenile diabetes. J Clin Lab Invest 28: 91-100

5. Mogensen CE, Andersen MJF (1973) Increased kidney size and glomerular filtration rate in early juvenile diabetes. Diabetes 22: 706-712

6. Mogensen CE (1976) Renal function changes in diabetes. Diabetes 25: 872-879

7. Moell $H$ (1961) Kidney size and its deviation from normal in acute renal failure. Acta Radiol 206 (Suppl): 5-31

8. Friedenberg JJ, Walz BJ, McAlister WH, Locksmith JP, Gallagher TL (1965) Roentgen size of normal kidneys. Radiology 84: $1022-1030$

9. Wahlefeld AW, Holz G, Bergmeyer HU (1974) Creatinine. In: Bergmeyer HU (ed) Methods of enzymatic analysis, 2nd edn. Verlag Chemie Weinheim and Academic Press, New York and London, pp 1786-1790

10. Bratton AC, Marshall EK (1939) A new coupling reagent for sulfanilamide determination. J Biol Chem 128: 537-545

11. Mogensen CE, Østerby R, Gundersen HJG (1979) Early functional and morphologic vascular renal consequences of the diabetic state. Diabetologia 17: 71-76

12. Johansen K, Hansen AP (1971) Diurnal serum growth hormone levels in poorly and well controlled juvenile diabetics. Diabetes 20: 239

13. Mogensen CE, Andersen MJF (1975) Increased kidney size and glomerular filtration rate in untreated juvenile diabetes. Normalization by insulin treatment. Diabetologia 11: 221-224

14. Brenner BM, Humes HD (1977) Mechanics of glomerular ultrafiltration. N Engl J Med 297: 148-154

15. Mogensen CE (1971) Kidney function and glomerular permeability to macromolecules in early juvenile diabetes. Scand J Clin Lab Invest 28: 79-90

16. Brochner-Mortensen J, Ditzel J, Mogensen CE, Rødbro P (1979) Microvascular permeability to albumin and glomerular filtration rate in diabetic and normal children. Diabetologia 16: $307-311$

17. Kroustrup JP, Gundersen HJG, Østerby R (1977) Glomerular size and structure in diabetes. III. Early enlargement of the capillary surface. Diabetologia 13: 207-210

18. Østerby R, Seyer-Hansen K, Gundersen HJG (1978) Rapid increase in filtration surface and basement membrane material in acute diabetes. Diabetologia 15: 259 (Abstract)

19. Østerby R, Gundersen HJG (1980) Fast accumulation of basement membrane material and the rate of morphological changes in acute experimental diabetic glomerular hypertrophy. Diabetologia 18: 493-500

20. Seyer-Hansen K, Hansen J, Gundersen HJG (1980) Renal hypertrophy in experimental diabetes. A morphometric study. Diabetologia 18: 501-505

21. Viberti GC (1979) Early functional and morphological changes in diabetic nephropathy. Clin Nephrol 12: 47-53

Received: 4 August 1980

and in revised form: 24 March 1981

J. García Puig

Ciudad Sanitaria La Paz

Departamento de Medicina Interna

Residencia General, Planta 10

Avenida del Generalísimo 177

Madrid 34, Spain 